\title{
MANAGING CLIMATE CHANGE
} AND EXPECTATIONS: WHAT IS \section{ENHANCED ROCK WEATHERING}

\section{REALISTICALLY CAPABLE OF?}

\author{
XAVIER DUPLA AND STEPHANIE GRAND
}

University of Lausanne

Presenting Author: xavier.dupla@unil.ch

Enhanced rock weathering (EW) is being promoted as a potentially powerful $\mathrm{CO}_{2}$-sequestering geoengineering technology against climate change. The dissolution, or weathering, of ground silicate sequesters indeed $\mathrm{CO}_{2}$ in stable forms (bicarbonate ions and carbonate minerals) at the anthropic time scale.

Results largely based on laboratory experiments have fueled global scenarios promising benefits both in terms of climate and soil fertility. A wide deployment of EW on agricultural soils is currently believed to be able to capture 0.5 to 2 billion tons of $\mathrm{CO}_{2}$ each year.

Based on recent thermodynamic, mineralogic and agronomic considerations, we critically review the limits that EW would face in natural conditions. Our study allows to identify the situations in which EW efficiency would be maximized and leads us to update its global $\mathrm{CO}_{2}$ sequestration potential. 